Sallyann T. Colbert MB FFA, Deirdre M. O'Hanlon MB FRCSI, *

Conor McDonnell MB, Fred H. Given FACS FRCSI, * Padraic W. Keane FFA

\section{Analgesia in day case breast biopsy - the value of pre-emptive tenoxicam}

Purpose: Inadequate analgesia is a major problem following ambulatory surgery. In this prospective randomised study, the use of pre-operative intravenous tenoxicam (a non steroidal anti-inflammatory agent) was compared with post-incision tenoxicam for the relief of post-operative pain in 77 patients undergoing day case breast biopsy.

Methods: All patients received a standard general anaesthetic which included infiltration of the wound with bupivacaine after skin closure. Intravenous tenoxicam $(20 \mathrm{mg}$ ) was administered as a single bolus either $30 \mathrm{~min}$ before surgery ( 37 patients) or after incision (40 patients). Pain scores ( $100 \mathrm{~mm}$ visual analog scale) were obtained at 30,60, 120 and $240 \mathrm{~min}$ after surgery analgesic requirements recorded.

Results: Both groups of patients were similar with respect to age, weight, operative time and length of the incision. Patients receiving the tenoxicam $30 \mathrm{~min}$ before surgery had lower pain scores at $30 \mathrm{~min}(22 \pm 3)$ vs $46 \pm 3$; $P<0.0001), 60 \mathrm{~min}(9 \pm 2$ vs $28 \pm 3) ; P<0.0001), 120 \mathrm{~min}(6 \pm 2$ vs $16 \pm 3) ; P=0.0002)$ and $240 \mathrm{~min}$ $(3 \pm 1)$ vs $7 \pm 2) ; P=0.02$ ) post-operatively. They had a longer time to first analgesia ( $55.1 \pm 4.6$ vs $29.6 \pm 2.6)$ $\min ; P=0.0004)$, required less meperidine (5.4 $\pm 2.6 \mathrm{vs} 18.8 \pm 3.9) \mathrm{mg} ; P=0.007)$ and were more likely not to require any further analgesia during the first four hours post-operatively.

Conclusion: Pre-operatively administered tenoxicam provides superior post-operative analgesia than tenoxicam administered after surgical incision in patients undergoing breast biopsy.

Objectif : L'analgésie inadéquate est un problème majeur en chirurgie ambulatoire. Dans cette étude aléatoire et prospective, on a comparé chez 77 patientes subissant une biopsie du sein sur une base ambulatoire l'effet du ténoxicam (un anti-inflammatoire non stérö̈dien) administré par voie intraveineuse avant l'opération à cette même médication administrée après l'incision.

Méthodes : Toutes les patientes ont reçu une anesthésie générale standard, incluant une infiltration de la plaie avec de la bupivacainne après fermeture de la peau. Le tenoxicam I.V. $(20 \mathrm{mg})$ a été administré en bolus $30 \mathrm{~min}$ avant la chirurgie ( 37 patientes) ou après l'incision ( 40 patientes). Le score de la douleur, en utilisant une échelle visuelle analogue de $100 \mathrm{~mm}$, a été obtenu à $30,60,120$ et 240 min après la chirurgie et les besoins en analgésiques ont été compilés.

Résultats : Les deux groupes de patientes étaient semblables quant à l'âge, au poids, à la durée de la chirurgie et à la longueur de l'incision. Les patientes qui ont reçu le ténoxicam $30 \mathrm{~min}$ avant l'opération ont présenté un score de douleur inférieur lors de toutes les évaluations: lors de $30 \mathrm{~min}, 22 \pm 3$ vs $46 \pm 3(P<0,000$ l), à 60 $\min , 9 \pm 2$ vs $28 \pm 3(P<0,0001)$, à $120 \mathrm{~min}, 6 \pm 2$ vs $16 \pm 3(P=0,0002)$, à $240 \mathrm{~min}, 3 \pm 1$ vs $7 \pm 2$ $(P=0,02)$. Ces patientes ont aussi présenté le plus long intervalle avant la lère demande d'analgésiques $(55,1 \pm$ $4,6$ vs $29,6 \pm 2,6 \mathrm{~min}),(P=0,0004)$, ont nécessité moins de mépéridine $(5,4 \pm 2,6$ vs $18,8 \pm 3,9 \mathrm{mg})$, $(P=0,007)$ et étaient plus susceptibles de ne requérir aucune autre analgésie durant les quatre premières heures post opératoires.

Conclusion : Le ténoxicam administré en période pré opératoire produit une analgésie post opératoire supérieure à celle obtenue par son administration après l'incision chez des patientes subissant une biopsie du sein.

From the Department of Anaesthesia and Surgery, ${ }^{*}$ University College Hospital, Galway, Ireland. Address correspondence to: Dr. Sallyann Colbert, Department of Anaesthesia, St. James Hospital, Dublin 8, Ireland. Accepted for publication December 21, 1997. 
I NADEQUATE analgesia is a problem following surgery and it has been demonstrated that one third of patients suffer moderate to severe postoperative pain due to inadequate analgesia. ${ }^{1-5}$ On demand intramuscular opioids fail to produce adequate pain relief in over $80 \%$ of patients. ${ }^{6}$ Apprehension concerning adverse side effects and addiction has contributed to under utilisation of prescribed opioids. Attention has focused on other methods of achieving analgesia such as the use of non-steroidal anti-inflammatory drugs (NSAID) and local anaesthesia. ${ }^{7-9}$ A combination of opioids, NSAIDs and long acting local anaesthetic agents provides good pain relief. In patients receiving general anaesthesia, a short acting opioid is usually given at induction to facilitate induction and to provide the initial operative analgesia. An NSAID can then be given, $p r$ or $i m$, to provide later analgesia. A long-acting local anaesthetic is often given at the end of surgery to provide post-operative analgesia. This combination is effective for pain relief in day case surgery. Non-steroidal anti-inflammatory drugs have been developed which are suitable for administration via the intravenous route and these have also proved beneficial in the relief of post-operative pain. ${ }^{10-11}$

Experimental animal studies have demonstrated that well-localised and brief noxious stimuli, perceived as pain, result in long lasting neuronal sensitisation resulting from alterations in central processing of stimuli. ${ }^{12-14}$ When this occurs such as following surgical trauma, innocuous stimuli may be perceived as pain. ${ }^{12,15-16}$ Injury may also induce a hyperexcitable state called "wind-up" in the dorsal horn neurons, in which constant peripheral input sequentially increases activity. These observations lead to the concept that analgesia administered before an initial noxious stimulus such as skin incision is more effective than the same dose given afterwards i.e., the concept of pre-emptive analgesia.

In experimental animal studies central sensitisation may be eliminated or reduced if the afferent barrage is prevented from reaching the central nervous system. Pre-injury neural blockade with local anaesthetics or opioids has been shown to reduce sensitisation and prevent the development of injury induced spinal hyperexcitability in animals. ${ }^{17-21}$ In spite of a sound theoretical base and encouraging animal studies the clinical value of pre-emptive analgesia remains unclear in view of conflicting clinical results.

Non-steroidal anti-inflammatory drugs are widely used in day case surgery ${ }^{7-9}$ and a number of recent studies have examined pre-emptive oral or rectal NSAIDs with varying results. ${ }^{22-26}$ The introduction of intravenous forms of these drugs facilitates examination of the role of NSAIDs as pre-emptive analgesic agents. There are few studies examining the effects of pre-emptive intravenous NSAIDs but two recent studies have found a beneficial effect. ${ }^{10-11}$ This study was established to evaluate and compare the efficacy of pre-emptive compared with post-incisional intravenous tenoxicam for post-operative analgesia in a series of patients undergoing day case breast biopsy.

\section{Materials and methods}

In this prospective randomised study, pain scores and analgesic requirements were examined in 77 patients undergoing day case breast biopsy between July 1996 and December 1996. Following ethics committee approval, patients who were ASA I or II were recruited into the study. The patients were enrolled and randomised according to a table of random numbers. The patients in group A received $20 \mathrm{mg}$ tenoxicam iv $30 \mathrm{~min}$ pre-operatively and patients in group $B$ received $20 \mathrm{mg}$ tenoxicam iv post-incision. Patients with contraindications to nonsteroidal analgesic use and those undergoing fine wire localised breast biopsy were excluded from the study.

All patients received a standard anaesthetic and no premedication was administered. This consisted of induction with $2 \mathrm{mg} \cdot \mathrm{kg}^{-1}$ propofol, followed by $5 \mu \mathrm{g} \cdot \mathrm{kg}^{-1}$ alfentanil and a laryngeal mask was inserted. The patient was allowed to breath spontaneously via a Bain circuit, anaesthesia being maintained with isoflurane in oxygen and nitrous oxide. All biopsies were performed by one of two surgeons and all patients received $10 \mathrm{ml}$ bupivacaine $0.5 \%$ infiltrated into the wound immediately after skin closure. The patients were prescribed $50 \mathrm{mg}$ meperidine $i m, 50 \mathrm{mg}$ diclofenac po or 250 or $500 \mathrm{mg}$ paracetamol po for post-operative analgesia and the choice of drug administered was at the discretion of the recovery nurse who had no knowledge of the group to which the patient belonged. Following full recovery the patients were discharged home with an escort and with oral diclofenac.

A proforma was completed on all the patients detailing name, medical records number, age, sex, weight, length of wound, duration of surgery, diagnosis and any ill effects post-operatively. A record was kept of pain scores at $30,60,120$ and $240 \mathrm{~min}$ after surgery. The pain score was assessed using a visual analogue scale (VAS) and these were scored from 0 to $100(0 \mathrm{~mm}$ no pain, $100 \mathrm{~mm}$ worst possible pain). The time to first analgesic requirement within four hours of surgery and the analgesics administered were recorded. Pain scores and analgesic requirements were assessed by an investigator without knowledge of the timing of tenoxicam administration.

Statistical analysis was performed using the MannWhitney $\mathrm{U}$ test, Spearmans correlation and the Chi square test with significance assumed at the $5 \%$ level. 


\section{Results}

Seventy-seven patients were enrolled in the study. The patients had a mean \pm SEM age of $42.2 \pm 1$ yr with a range from 21 to $76 \mathrm{yr}$. There were 37 patients in group A (20 mg tenoxicam ad $30 \mathrm{~min}$ before surgery) and 40 patients in group $B$ ( $20 \mathrm{mg}$ tenoxicam post-incision).

There were no differences between the groups with respect to age, duration of surgery, length of the wound or the weight of the patient (Table I). There were no correlations between the pain scores at any of the time periods and the age or weight of the patient, the length of the wound or the duration of surgery. There were differences between the two groups with respect to time to first analgesia, the dose of meperidine administered post-operatively, but no differences were observed for the dose of diclofenac or paracetamol administered during the first four hours after surgery (Tables I, II). Differences were observed in the pain scores at 30,60, 120 and at 240 min post operatively (Table II). Patients receiving a pre-emptive dose of tenoxicam were less likely to require meperidine post-operatively and more likely not to require any further analgesia during the first four hours post-operatively (Table III).

Frozen sections were performed on clinically, cytologically or mammographically suspicious lesions. Twelve patients had carcinoma diagnosed; six in group A and six in group B. Patients with cancer were admitted for in-patient counselling and further treat- ment. No patients in this study required admission because of poor pain control. One patient required admission for investigation following an episode of an unexplained arrhythmia post-operatively.

\section{Discussion}

The role of pre-emptive analgesia has a sound theoretical basis but many clinical studies have not borne out the favourable results produced in animal studies. A number of studies have produced encouraging results. Ringrose and $\mathrm{Cross}^{27}$ found pre-operative femoral nerve block to be more effective in preventing post-operative pain than post-operative femoral nerve block in patients undergoing knee joint reconstruction. However, the patients in that study were not randomised. Ejlersen et al. ${ }^{28}$ examined pain scores and further analgesic requirements in patients undergoing elective inguinal herniotomy. They compared pre and post-incision wound infiltration with lidocaine $1 \%$ and found a benefit for the pre-incision group in time to first analgesia, use of supplemental analgesia but there were no significant differences in pain scores. Turner and Chalkiadis ${ }^{29}$ found little benefit with pre-emptive lidocaine wound infiltration in patients undergoing appendicectomy, while Dierking $e t a l^{30}$ and Dahl $e t a l .^{31}$ similarly found no benefit following the use of pre-emptive nerve blockade or extradural block for post-operative pain relief. Katz et al. ${ }^{32}$ examined pain relief following the use of pre-emptive compared with

TABLE I Demographic data.

\begin{tabular}{lll}
\hline Variable & Group $A$ & Group $B$ \\
\hline Age (yr) & $42.5 \pm 2.3$ & $41.9 \pm 1.9$ \\
Weight (kg) & $63.4 \pm 1.9$ & $62.8 \pm 1.2$ \\
Duration of surgery (min) & $26.7 \pm 1.0$ & $25.7 \pm 0.8$ \\
Length of wound (cm) & $3.4 \pm 0.1$ & $3.4 \pm 0.7$ \\
Diclofenac (mg first 4 hr) & $13.5 \pm 3.7$ & $21.3 \pm 3.9$ \\
Paracetamol (mg first 4 hr) & $128.4 \pm 33.0$ & $75.0 \pm 27.1$ \\
\hline
\end{tabular}

Group A pre-emptive and group B post-incision tenoxicam.

Mean value \pm SEM. No significant changes between groups.

TABLE III Further analgesic use during the first four hours post-operatively.

\begin{tabular}{llll}
\hline Variable & Group $A$ & Group $B$ & $P$ \\
\hline No further analgesia used & $14 \pm 37.8 \%$ & $2 \pm 5.0 \%$ & 0.0004 \\
Paracetamol alone used & $10 \pm 27.0 \%$ & $7 \pm 17.5 \%$ & ns \\
NSAIDs or meperidine used & $13 \pm 35.1 \%$ & $31 \pm 77.5 \%$ & 0.0002 \\
Meperidine used & $4 \pm 10.8 \%$ & $15 \pm 37.5 \%$ & 0.007 \\
\hline
\end{tabular}

Group A pre-emptive and group B post-incision tenoxicam. Data given as number (percent). Statistics used Chi square, $\mathrm{ns}=$ not significant

TABLE II Time to first analgesia, meperidine used in the first four hours post-operatively and pain scores at intervals post-operatively in the two groups.

\begin{tabular}{llll}
\hline Variable & Group $A$ & Group B & $P$ \\
\hline First analgesia (min) & $55.1 \pm 4.6[45.7-64.6]$ & $29.6 \pm 2.6[24.4-34.8]$ & 0.0004 \\
Meperidine (mg first 4 hr) & $5.4 \pm 2.6[0.2-10.6]$ & $18.8 \pm 3.9[10.9-26.6]$ & 0.007 \\
VAS 30 min & $22 \pm 3[15-28]$ & $46 \pm 3[39-52]$ & $<0.0001$ \\
VAS 60 min & $9 \pm 2[6-13]$ & $28 \pm 3[23-33]$ & $<0.0001$ \\
VAS 120 min & $6 \pm 2[2-9]$ & $16 \pm 3[11-21]$ & 0.0002 \\
VAS 240 min & $3 \pm 1[0-5]$ & $7 \pm 2[3-11]$ & 0.02 \\
\hline
\end{tabular}

Group A pre-emptive and group B post-incision tenoxicam. Results \pm SEM and [95\% confidence intervals for the mean]. 
post-incision epidural fentanyl in 30 patients undergoing thoracotomy. They found better pain scores six hours after surgery and less use of opioids 12-24 hr following surgery in the group treated pre-emptively. Further studies have been designed to show that analgesic intervention made before surgery is more effective than no intervention at all and then a conclusion has been reached that this provides evidence for a pre-emptive beneficial effect. Several NSAID premedication studies have shown this. ${ }^{33-35} \mathrm{~A}$ number of studies have examined oral or rectal pre-emptive NSAIDs. Some have found beneficial effects but many have shown no benefits. ${ }^{22-26}$

In light of these clinical studies, the results from the present study were surprisingly good. Beneficial effects were found for pain scores at 30,60, 120 and $240 \mathrm{~min}$ post-operatively, time to first analgesia, opioid use and in the number of patients not requiring further analgesia with pre-emptive compared with post-incision tenoxicam. The pre-emptive group scored better in all the "pain" parameters examined apart from the use of diclofenac and paracetamol in the first four hours post-operatively. One limitation of this study is the short period of observation after surgery. The study was designed to examine immediate post-operative pain and further observation for a delayed effect warrants further review. Similar benefits were observed in two previous studies examining intravenous NSAIDs. Fletcher et al. $(1995)^{10}$ and Rogers et al. (1995) ${ }^{11}$ found pre-emptive ketorolac to be of benefit for early for early post-operative pain relief. Similar results were found in the present study.

The precise mode of action of tenoxicam, in common with all non-steroidals, is unknown and is probably multifactorial. Non steroidal anti-inflammatory drugs inhibit prostaglandin synthesis by inhibiting cyclo-oxygenase which catalyses the formation of cyclic endoperoxidases from arachidonic acid. ${ }^{36}$ They inhibit conversion of arachidonic acid to prostaglandins which have a role in promoting pain and hyperalgesia associated with tissue trauma and inflammation. Non steroidal anti-inflammatory drugs also have an inhibitory effect on neutrophil chemotaxis and neutrophil and monocyte phagocytosis. $^{37}$ Tenoxicam scavenges active oxygen radicals or inhibit the generation of oxygen radicals at the inflammatory site and this has been postulated as underlying some of its anti-inflammatory actions. ${ }^{38}$ Non steroidal anti inflammatory drugs also have effects in the central nervous system. A correlation has been demonstrated between the analgesia induced by sodium salicylate and an increased turnover of dopamine, noradrenaline and serotonin. ${ }^{39,40}$ Serotoninergic and/or dopaminergic mechanisms may be relevant to the antinociceptive effects of aspirin and other NSAIDs. ${ }^{40}$
Surgical trauma generates powerful nociceptive impulses which are generated by the procedure itself and by the action of proteolytic and inflammatory agents released following tissue injury. The release of prostaglandins during tissue damage is considered to enhance the action of bradykinin and other noxious agents on nociceptors and hence accentuate pain. ${ }^{41}$ This release of inflammatory mediators and subsequent oedema may result in pain for several hours after tissue injury. The ability of NSAIDs to inhibit prostaglandin synthesis in these situations can result in very effective analgesia. Non steroidal anti-inflammatory drugs when given before tissue damage may prevent nociceptor sensitisation and reduce the CNS bombardment described by Wall. ${ }^{42}$ Campbell et al. ${ }^{35}$ found that intravenous diclofenac provided better post-operative analgesia than intravenous fentanyl and postulated that the beneficial effects of diclofenac resulted from inhibition of prostaglandin synthesis before tissue disruption.

Intramuscular administration of tenoxicam and diclofenac takes $15 \mathrm{~min}$ to reach levels $290 \%$ of the maximally achieved concentration. The same drugs administered intravenously reach peak serum concentrations much faster and these decline over the following two hours mainly due to distribution processes. ${ }^{37}$ Administration of intravenous agents $30 \mathrm{~min}$ pre-operatively is inconvenient in the clinical setting. Perhaps giving an intravenous agent $10 \mathrm{~min}$ or immediately before incision would produce similar benefits to those observed in this study. This aspect of tenoxicam use merits further study.

The present study supports the contention that preventing pain or reducing its impact may make subsequent management easier. ${ }^{42}$ McQuay and Dickinson ${ }^{14}$ suggest that different drug classes have at least an additive analgesic effect and utilise distinct primary mechanisms. They suggest that strategies for pharmacological management of pain based on drugs which block all transmitters may be more successful than those based on antagonism of one specific transmitter alone. The suggestion is that a triad of opioid, local anaesthetic and NSAIDs is necessary to produce maximal reduction in pain intensity. In the present study these three different classes of analgesics were employed and in spite of the combination, pre-emptive delivery of tenoxicam proved superior to post-incisional tenoxicam.

In conclusion, in this prospective randomised trial, intravenous tenoxicam $(20 \mathrm{mg})$ was administered as a single bolus either $30 \mathrm{~min}$ before surgery ( 37 patients) or after incision ( 40 patients). Patients receiving preemptive tenoxicam had lower pain scores at 30,60 , 120 and $240 \mathrm{~min}$ post-operatively, had a longer time to first analgesia, required less meperidine and were 
more likely not to require any further analgesia during the first four hours post-operatively. Pre-emptive tenoxicam should be considered in all patients undergoing day case surgery, who do not have contraindications to NSAID use.

\section{References}

1 Cohen FL. Postsurgical pain relief: patients status and nurses medication choices. Pain 1980; 9: 265-74.

2 Donovan BD. Patient attitudes to postoperative pain relief. Anaesth Intensive Care 1983; 11: 125-9.

3 Keats AS. Postoperative pain: research and treatment. J Chronic Dis 1956; 4: 72-83.

4 Papper EM, Brodie BB, Rovenstine EA. Postoperative pain: its use in the comparative evaluation of analgesics. Surgery 1952; 32: 107-9.

5 Tammisto T. Analgesics in postoperative pain relief. Acta Anaesthesiol Scand 1978; 70(Suppl): 47-50.

6 Kuhn S, Cooke K, Collins M, Jones JM, Mucklow JC. Perceptions of pain relief after surgery. BMJ 1990; 300: 1687-90.

7 Brown DI, Carpenter RL. Perioperative analgesia: a review of risks and benifits. J Cardiothorac Vasc Anesth 1990; 4: 368-83.

8 Buchanan JM, Halshaw J, Baldasera J, Dallard JK, Poole PH. Postoperative pain relief: a new approach: narcotics compared with non-steroidal anti-inflammatory drugs. Ann R Coll Surg Engl 1988; 70: 332-5.

$9 \mathrm{Lutz} J$, Lamer TJ. Management of postoperative pain: review of current techniques and methods. Mayo Clin Proc 1990; 65: 584-96.

10 Fletcher D, Zetlaoui P, Monin S, Bombart M, Samii $K$. Influence of timing on the analgesic effect of intravenous ketorolac after orthopedic surgery. Pain 1995; 61: 291-7.

11 Rodgers JE, Fleming BG, Macintosh KC, Jobnston B, Morgan-Hughes JO. Effect of timing of ketorolac administration on patient-controlled opioid use. Br J Anaesth 1995; 75: 15-8.

12 Woolf CJ. Central mechanisms of acute pain. In: Bond MR, Charlton JE, Woolf CJ (Eds.). Proceedings of the 6th World Congress on Pain. Amsterdam: Elsevier, 1991: 25-34.

13 Dubner $R$. Neuronal plasticity and pain following peripheral tissue inflammation or nerve injury. In: Bond MR, Charlton JE, Woolf CJ (Eds.). Proceedings of the 6th World Congress on Pain. Amsterdam: Elsevier, 1991: 263-76.

$14 M c Q$ uay HJ, Dickenson $A H$. Implications of nervous system plasticity for pain management (Editorial). Anaesthesia 1990; 45: 101-2.

15 CJ Woolf. Recent advances in pathophysiology of acute pain. Br J Anaesth 1989; 63: 139-46.
16 Torebjörk E, Lundberg L, La Motte R. Neural mechanisms for capsaicin-induced hyperalgesia. Pain 1990; (Suppl 5): S114.

17 Akerman B, Arweström E, Post C. Local anesthetics potentiate spinal morphine antinociception. Anesth Analg 1988; 67: 943-8.

18 Woolf CJ, Wall PD. Morphine-sensitive and morphineinsensitive actions of $C$ fibre input on the rat spinal cord. Neurosci Lett 1986; 64: 221-5.

19 Dickenson $A H$, Sullivan $A F$. Subcutaenous form alin-induced activity of dorsal horn neurons in the rat: differential response to an intrathecal opiate administered pre or post formalin. Pain 1987; 30: 349-60.

20 Coderre TJ, Melzack R. Cutaneous hyperalgesia: contributions of the peripheral and central nervous systems to the increase in pain sensitivity after injury. Brain Res 1987; 404: 95-106.

21 Coderre TJ, Vaccarino AL, Melzack R. Central nervous system plasticity in the tonic pain response to subcutaenous formalin injection. Brain Res 1990; 535: 155-8.

22 Sisk AL, Mosley RO, Martin RP. Comparison of preoperative and postoperative diflunisal for suppression of postoperative pain. J Oral Maxillofac Surg 1989; 47: 464-8.

23 Sisk $A L$, Grover BJ. A comparison of preoperative and postoperative naproxen sodium for suppression of postoperative pain. J Oral Maxillofac Surg 1990; 48: 674-8.

24 Murphy DF, Medley C. Preoperative indomethacin for pain relief after thoracotomy: comparison with postoperative indomethacin. $\mathrm{Br} J$ Anaesth 1993; 70: 298-300.

25 O'Hanlon JJ, Muldoon T, Lowry D, McCleane G. Improved postoperative analgesia with preoperative piroxicam. Can J Anaesth 1996; 43: 102-5.

26 Buggey DJ, Wall C, Carton EG. Preoperative or postoperative diclofenac for laparoscopic tubal ligation. Br J Anaesth 1994; 73: 767-70.

27 Ringrose NH, Cross $M J$. Femoral nerve block in knee joint surgery. Am J Sports Med 1984; 12: 398-402.

28 Ejlersen E, Andersen HB, Eliasen K, Mogensen T. A comparison between preincisional and postincisional infiltration and postoperative pain. Anesth Analg 1992; 74: 495-8.

29 Turner GA, Chalkiadis $G$. Comparison of preoperative with postoperative lignocaine infiltration on postoperative analgesic requirements. $\mathrm{Br} J$ Anaesth 1994; 72: 541-3.

30 Dierking GW, Dabl JB, Kanstrup J, Dabl A, Keblet H. Effect of pre-ps postoperative inguinal field block on postoperative pain after herniorrhaphy. $\mathrm{Br} \mathrm{J}$ Anaesth 1992; 68: 344-8.

31 Dabl JB, Hansen BL, Hjortso NC, Erichsen CJ, Moiniche S, Keblet $H$. Influence of timing on the effect of continuous extradural analgesia with bupivacaine and morphine after major abdominal surgery. Br J Anaesth 1992; 69: 4-8. 
32 Katz J, Kavanagh BP, Sandler $A N$, et al. Clinical evidence of neuroplasticity contributing to postoperative pain. Anesthesiology 1992; 77: 439-46.

33 Hutchinson GL, Crofts SL, Gray IG. Preoperative piroxicam for postoperative analgaesia in dental surgery. Br J Anaesth 1990; 65: 500-3.

34 McGlew IC, Angliss DB, Gee GJ, Rutherford A, Wood ATA. A comparison of rectal indomethacin with placebo for pain relief following spinal surgery. Anaesth Intensive Care 1991; 19: 40-5.

35 Campbell WI, Kendrick R, Patterson C. Intravenous divclofenac sodium. Does its administration before operation suppress postoperative pain? Anaesthesia 1990; 45: 763-6.

36 Vane JR. Mode of action of aspirin and similar com. pounds. In: Robinson HJ, Vane JR (Eds.). Prostaglandin Synthetase Inhibitors. Their Effects on Physiological Functions and Pathological States. New York: Raven Press, 1974: 155-63.

37 Gonzalez JP, Todd PA. Tenoxicam. A preliminary review of its pharmacodynamic and pharmacokinetic properties, and therapeutic efficacy. Drugs 1987; 34: 289-310.

38 Ichibara S, Ichibara $\Upsilon$, Nakayama $S$, et al. Metabolic fate of tenoxicam and a possible mechanism of antiinflammatory activity. J Pharmacobio-Dynamics 1985; 8(Suppl): 158.

39 Bensemana D, Gascon AL. Relationship between analgesia and turnover of brain biogenic amines. Can J Physiol Pharmacol 1978; 56: 721-30.

40 McCormack $K$, Brune $K$. Dissociation between the antinociceptive and anti-inflammatory effects of the nonsteroidal anti-inflammatory drugs. A survey of their analgesic efficacy. Drugs 1991; 41: 533-47.

41 Ferreira SH, Moncada S, Vane JR. Prostaglandins and the mechanism of analgesia produced by aspirin-like drugs. Br J Pharmacol 1973; 49: 86-97.

42 Wall $P D$. The prevention of postoperative pain (Editorial). Pain 1988; 33: 289-90. 